\title{
Representações Sociais de Crack e Adolescência na Imprensa Pernambucana
}

\author{
Daniel Henrique Pereira Espíndula ${ }^{1}$ \\ Colegiado de Psicologia da Universidade Federal do Vale do São Francisco, \\ Petrolina, PE, Brasil \\ Larissa dos Santos Alves \\ Lauriston de Araújo Carvalho \\ Programa de Pós-Graduação em Psicologia da Universidade Federal do Espírito Santo, \\ Vitória, ES, Brasil \\ Marianna Barbosa Almeida \\ Programa de Pós-Graduação em Psicologia da Universidade Federal de Pernambuco, \\ Recife, PE, Brasil \\ Suzyelaine Tamarindo Marques Cruz \\ Programa de Pós-Graduação em Psicologia da Universidade Federal do Espírito Santo, \\ Vitória, ES, Brasil
}

\begin{abstract}
Resumo
Surgido nos anos 80, o crack tornou-se rapidamente temido e perigoso, sendo a adolescência o grupo vulnerável ao envolvimento. Este estudo investigou as representações da imprensa sobre o crack e adolescência. A coleta ocorreu no Jornal do Commercio-PE entre julho/2009 a junho/2010, resultando em 117 matérias. Os dados foram analisados pelo sofware Alceste, que apontou seis classes agrupadas em dois eixos: ações de enfrentamento - políticas públicas, ações sociais, busca pelo tratamento e, consumo de outras drogas. O segundo criminalidade e droga - marcados pela prisão e morte. O crack é representado como uma pedra, e a morte como elemento de objetivação. A associação entre crack e adolescência resulta na dependência, mortes e prisões, sendo o tratamento uma alternativa buscada, mas quase nunca alcançada.
\end{abstract}

Palavras-chave: Representação social, adolescente, crack.

\section{Social Representations of Crack and Adolescence in Pernambuco's Media}

\begin{abstract}
Appeared in the $80 \mathrm{~s}$, the crack quickly became feared and dangerous, adolescence appears as a vulnerable group because of its involvement. This study aimed to observe the representations of the media from Pernambuco referring to the relationship between crack and adolescence. The search was conducted in

Endereço para correspondência: Universidade Federal do Vale do São Francisco, Colegiado de Psicologia, Avenida José de Sá Maniçoba, s/n, Centro, Petrolina, PE, Brasil 56304-205. Fone/Fax: (87) 2101-6868. E-mail: daniel.espindula@univasf.edu.br, larissa_alves_25@hotmail.com, lauristonac@hotmail.com, mariannabalmeida@gmail.com e suzy_diva@hotmail.com

Apoio financeiro: Conselho Nacional de Desenvolvimento Científico e Tecnológico (CNPq)/Programa Institucional de Bolsas de Iniciação Científica (PIBIC).
\end{abstract}


the "Jornal do Commercio-PE", from July/2009 to June/2010, resulting in a total of 117 reportages. Data were analyzed through the Alceste sofware. The results point to six classes grouped around two main axes: coping actions - public policy, social action, quest for the treatment and use of other drugs. The second, crime and drugs - characterized by the imprisonment and death. The crack is represented as a stone, and death comes as another element of objectification. The combination of crack and adolescence results in most cases in deaths and imprisonments, the treatment is an alternative sought but hard to be achieved.

Keywords: Social representation, adolescent, crack.

\section{Representaciones Sociales de Crack y Adolescentes en Prensa Pernambucana}

\section{Resumen}

Surgido en los años 80, el crack se convirtió rápidamente en un producto temido y peligroso, siendo los adolescentes uno de los grupos vulnerables al uso. Este estudio investigó las representaciones de la prensa sobre el crack y la adolescencia. La recolección de datos ocurrió en el Jornal do Comercio PE entre Julio del 2009 a Junio del 2010, con un resultado de 117 articulos. Los datos fueron analizados por el software Alceste, que anotó cinco clases agrupadas en dos áreas: acciones de afrontamiento-orden público, acción social, búsqueda de tratamiento y el uso de otras drogas. El segundo, sobre el crimen y las drogas-marcado por la detención y la muerte. El crack se representa como una piedra y la muerte como un elemento de objetivación. La asociación entre el crack y la adolescencia tiene como resultado muertes y arrestos. El tratamiento es una búsqueda alternativa, pero rara vez es alcanzada.

Palabras clave: Representación social, adolescente, crack.

Na contemporaneidade, o consumo de substâncias psicoativas evidenciado pelo seu uso/ abuso passou a ser visto como um problema de ordem social e pública, devendo ser combatido pelos serviços de segurança, justiça, saúde e educação, afetando diversos países desde meados do século XIX (J. F. Oliveira, McCallum, \& Costa, 2010; E. F. Silva, Pavani, Moraes, \& Chiaravalloti, 2006). Contudo, a noção do que é considerado uso/abuso de certas substâncias, bem como a forma, a quantidade e a aplicação é construída nas trocas de saberes e práticas a partir das conversas e trocas cotidianas representadas nas normas sócio-históricas em diversos grupos. Diferentes sociedades ao longo da história vêm considerando diversas substâncias ora líticas, ora ilícitas, como salienta J. F. Oliveira et al. (2010).

Dentre as diversas substâncias ilíticas encontradas atualmente na sociedade brasileira, chamamos atenção especial para o crack. Apresentada como uma substância devastadora e de fácil dependência, este tipo de substância tem suscitado aversão, temor e discussões em vários setores sociais.

É de conhecimento geral que o crack é uma droga em formato de pedra. No entanto, L. G. Oliveira e Nappo (2008) salientam que antigamente o crack era consumido em forma de "casca" ou flocos, e que o formato de pedra apenas passou a ser utilizado após a sua produção e comercialização em larga escala pelos traficantes, sendo a unidade vendida a baixo custo, pelo tamanho ou peso, o que a fez ser conhecida com uma droga mais barata que as demais.

Em levantamento recente realizado pela Fundação Osvaldo Cruz (Fiocruz) em parceria com a Secretaria Nacional de Políticas sobre Drogas (2013), visando delinear o perfil e o número da população usuária de crack no país, verificou-se que para as 27 capitais pesquisadas, aproximadamente 1 milhão de habitantes seriam usuários de substâncias ílíticas, desse montante, $35 \%$ fazem uso de crack e/ou substâncias simila- 
res. O mesmo estudo revelou ainda que, as capitais da região nordeste, foram as que apresentaram maior quantitativo de usuários de crack e/ou substâncias similares, quando considerado seu uso de forma regular. O estudo também reportou o envolvimento de jovens e adolescentes com o consumo do crack. Cerca de 14\% dos usuários são menores de idade.

Apesar do uso do crack ser considerado alarmante por parte dos serviços de saúde e segurança pública, conforme pode ser visto em propagandas públicas, programas de rádio e $\mathrm{TV}$, por exemplo, pesquisas têm apontado a existência do uso controlado, em longo prazo, não-diário e racional do crack nos Estados Unidos e no Brasil, através de estratégias de autocontrole por parte do usuário (German \& Sterk, 2002; Nappo, Galduróz, Raymundo, \& Carlini, 1999; Silveira \& Rodrigues, 2013). Para estes usuários, o consumo controlado do crack foi caracterizado pelo uso não-diário da droga e conciliado a práticas sociais pré-existentes, como a família, escola, trabalho, etc., o que estaria indicando de certo modo estratégias de prevenção ao uso abusivo da substância. Estas práticas, por sua vez, constituem barreiras protetivas contra o envolvimento de atos ilícitos, riscos e agravos contra a saúde, não surgindo entre estes os sintomas fisiológicos e sociais que constituiriam a dependência (Chen $\&$ Anthony, 2004). Apesar desses achados, Silveira e Rodrigues (2013), verificaram que o padrão do uso compulsivo ainda era o mais comumente observado. Os usuários do crack não conseguiam manter o controle sobre o seu uso em decorrência da fissura associada à droga.

Dentre os diversos grupos e segmentos sociais vistos como vulneráveis ao envolvimento com o crack, encontramos os jovens e os adolescentes. Considerada como uma época de exposição a diversos fatores de risco, a adolescência/juventude parece ser o alvo preferencial das campanhas e políticas de combate ao enfrentamento da questão. Na literatura científica é possível encontrar vários estudos que buscaram investigar a relação entre o consumo de substâncias ilíticas com os grupos adolescentes/juvenis e o desenvolvimento de políticas de prevenção ao uso/abuso (Baus, Kupek, \& Pires, 2002;
Guimarães, Godinho, Cruz, Kappann, \& Tosta, 2004). Outros estudos enfocam a relação entre o uso abusivo de substâncias ilíticas e a adolescência no Brasil e a ocorrência que os problemas relacionadas às repercussões que o consumo de drogas pode causar ao longo do ciclo de vida (De Micheli \& Formigoni, 2004; Guimarães et al., 2004; Soldera, Dalgalarrondo, Corrêa, \& Silva, 2004).

Para o senso comum, o crack é representado como uma droga que causa dependência rapidamente e de alto poder destrutivo, e que leva à morte. Os jovens e adolescentes corresponderiam ao grupo social mais vulnerável ao envolvimento. $\mathrm{O}$ debate em torno do envolvimento de jovens com o crack está lançado na mídia e nas conversas cotidianas, gerando discussões, conflitos, temores e interesses por parte da sociedade.

Diante desse impasse e atravessamentos a Teoria das Representações Sociais (TRS), enquanto uma teoria cognitiva de base psicossociológica se apresenta como uma ferramenta capaz de analisar o modo como os atores em suas trocas cotidianas significam os fenômenos sociais, dentre eles, a relação entre o crack e a adolescência, bem como compreender o modo como a imprensa veicula e divulga essas representações. Para Jodelet (2001), as representações sociais corresponderiam a guias de ação, capazes de nomear e definir os diversos aspectos da vida cotidiana, levando a tomadas de decisões e, eventualmente, posicionar-se frente a eles de forma defensiva.

Na literatura brasileira é possível encontrar alguns estudos que tratam da temática do uso/ abuso de substâncias psicoativas a partir da TRS. Em um estudo desenvolvido por Coutinho, Araújo e Gontiès (2004), os autores verificaram as representações de estudantes concluintes de cursos superiores a respeito do uso da maconha. Araújo, Castanha, Barros, e Castanha (2006) investigaram as representações de agentes comunitários de saúde sobre o consumo da maconha, enquanto Fonseca, Azevedo, Araújo, Oliveira, e Coutinho (2007), investigaram o consumo de maconha entre estudantes de Psicologia. O consumo de álcool e outras drogas por parte de usuários de Centros de Atenção Psicossocial Álcool e Dro- 
gas (CAPS-ad) e a relação desse consumo com as Infecções Sexualmente Transmissíveis (ISTs) foi objeto de estudo de Giacomozzi (2011). A dinâmica familiar dos usuários de drogas foi investigada por Medeiros, Maciel, Sousa, Tenorio-Sousa, e Dias (2013). Apenas um estudo buscou investigar as representações sociais da cocaína, a partir da compreensão dos estudantes universitários, Araújo, Gontiès e Nunes (2007). Apenas dois estudos enfocaram a representação social do crack: Noto, Pinsky e Mastroianni (2006) e Santos, Acioli e Sousa (2012).

Uma questão levantada ao se avaliar a produção científica nacional a respeito da temática da TRS está na baixa produção científica nacional sobre os processos midiáticos frente aos processos grupais. Tal fato pode ser conseqüência da tradução parcial da obra seminal de Moscovici (1961), aliada as dificuldades de acesso à obra e língua francofônica. Tal fato pode ser verificado quando se procurou por estudos que enfocaram a temática da drogadição e mídia. Coincidentemente, os dois estudos que discutiam a representação social do crack, Noto et al. (2006) e Santos et al. (2012) enfocaram a imprensa. Mas mesmo assim, ainda é possível perceber uma escassez de estudos sob enfoque da mídia nas representações sociais, denotando a necessidade de se conhecer mais os processos representacionais difundidos pela mídia.

Schiele e Boucher (2001), salientam que a comunicação exerce papel preponderante para a formação e desenvolvimento das representações sociais. Segundo os autores, as representações sociais são elaboradas no interior das relações comunicativas, chegando a repercutir sobre as interações e mudanças sociais. Nesse sentido, a mídia assumiria o lugar das relações sociais diretas entre os indivíduos.

Ao propor estudos que investiguem a representação de fenômenos recentes e ainda pouco estudados como o crack à luz das representações sociais, aliado a um espaço pouco explorado pela TRS - a imprensa - que se observa a relevância do presente estudo. Desse modo, o objetivo deste artigo consistiu em investigar como a mídia representa e apresenta a relação entre o crack e adolescência/juventude.

\section{Método}

\section{Delineamento e Fonte de Dados}

A pesquisa caracteriza-se por ser de caráter qualitativo, utilizando como fontes reportagens publicadas em um jornal de grande circulação em Pernambuco, sendo considerado o jornal mais lido do estado. A coleta dos dados se deu junto ao Jornal do Commercio na sua modalidade impressa e on-line. O motivo da escolha das duas versões deu-se pelo fato de que as matérias que estavam disponíveis on-line nem sempre saíam impressas e vice-versa.

\section{Procedimento de Coleta e Classificação dos Dados}

O procedimento de coleta e seleção das reportagens se deu a partir de uma busca sistemática tendo as seguintes palavras-chave como descritoras: crack adolescência; crack adolescente; crack adolescentes; crack juventude; crack jovem; crack jovens. Realizamos uma busca nos bancos de dados nas publicações impressas e on-line em todos os dias a partir julho/2009 a junho/2010, resultando em um total de 117 matérias.

Durante a preparação para a análise dos dados, as reportagens foram classificadas segundo alguns critérios pré-estabelecidos: fonte $d a$ reportagem; mês e ano de publicação; caderno; local em que se deu o fato (Recife e região metropolitana, Agreste, sertão, fora do estado).

\section{Procedimento de Análise de Dados}

Terminado o processo de coleta, o material passou por um processo de classificação e seriação pelo número de entrada no banco de dados, mês e ano, fonte, caderno e local em que se deu o fato. Para efeito de contagem, classificação e seriação, as reportagens que apareceram mais de uma vez durante o processo de busca foram contadas e classificadas apenas uma vez. Após a classificação e montagem do banco de dados, este foi analisado pelo software Alceste-Analyse de Lexémes Coocurrent dans les Ennoncés Simples d'un Texte - Reinert (1990), o qual realizou uma classificação descendente hierár- 
quica a partir da distribuição das palavras mais características presentes nos enunciados. Após o processo de classificação hierárquica, as classes apresentadas pelo software foram analisadas como categorias de sentido para a representação da relação entre adolescente $\mathrm{x}$ crack, buscando-se no interior de cada classe os elementos de objetivação e ancoragem.

\section{Resultados e Discussão}

Os resultados apontam para seis classes agrupadas em torno de dois grandes eixos: ações de enfrentamento - formado pela classe 01 (Politicas Públicas); classe 02 (Ações Sociais); classe 06 (Busca pelo tratamento) e, classe 04 (Consumo de outras drogas). O segundo eixo é marcado pela relação da criminalidade e o $\mathbf{c r a -}$ $\boldsymbol{c k}$. Este eixo é formado pelas classes 03 (Consequências para o jovem); e classe 05 (Prisão e morte), conforme o dendrograma apresentado na Figura 1.

A apresentação dos resultados será dada pela apresentação de cada classe no interior dos eixos, em que serão apontadas para cada uma suas principais características, significados e relações com as demais.

A classe 01 (Politicas Públicas - Estado) é fruto de um caderno especial com entrevista do então governador do estado sobre as políticas públicas necessárias para o desenvolvimento do estado de Pernambuco em suas diversas ordens, dentre elas saúde, educação e cidadania. Apesar do crack ser considerado uma questão de saúde pública, (Raupp \& Adorno, 2011), as ações que se destacam no combate e enfrentamento da droga, estão voltadas para as áreas de segurança pública com o reaparelhamento do sistema policial e não pela implementação ou propostas de políticas públicas de saúde, voltados ao enfrentamento do crack, conforme podemos observar no trecho selecionado pelo programa como sendo mais significativo:

Há um processo de mudança na política de segurança. Tivemos resultados qualitativos e quantitativos. $\mathrm{Na}$ área de qualidade, colocamos a segurança como questão não só de polícia, mas resultado de um processo histórico, da desarrumação social, da importância na educação, cultura, esporte, mediação de conflitos. ("As Imagens", 2009)

O fato de não citar a área da saúde articulada à rede de cuidados e serviços para o enfrentamento da droga nos faz pensar como podem estar sendo pautadas as políticas públicas. Um problema social que deveria ser analisado a partir da ótica da prevenção e atuação em saúde, passa a ser visto como uma questão criminal e de justiça. Ao sair da esfera da saúde para o segmento criminal, os usuários de crack deixam de ser compreendidos como um sujeito que precisa de cuidados à saúde e passam a ser representados como um criminoso ou alguém que infringiu as leis.

Esta lógica parece estar ancorada no modelo norte-americano discutido por Rodrigues (2002), em que o combate ao tráfico de drogas está amparado em bases morais e médico-sanitárias. As políticas voltadas ao usuário são decididas na esfera jurídica nos tribunais, cabendo ao condenado cumprir o tratamento/pena. Ao passo que o governo do estado insiste no combate das drogas pelo meio da repressão, Santoucy, Conceição e Sudbrack (2010) salientam que as medidas repressivas têm provocado mais prejuízos e perdas humanas do que o próprio efeito deletério das drogas.

As classes 02 (Movimentos Sociais - parcerias com o Estado) e 06 (Busca pelo tratamento) enfocam a busca pelo tratamento do adolescente, com a diferença que a classe 02 discute a participação dos movimentos sociais no tratamento da dependência e a 06 o desespero das mães em conseguir um abrigo ou espaço de tratamento para o filho.

A igreja presbiteriana se aliou ao governo do estado na luta contra o crack. Em reunião realizada, nessa quinta-feira, 03 , entre representantes da secretaria de desenvolvimento social e direitos humanos de Pernambuco e dezenas de pastores se reuniram para discutir o acordo. (Classe 02 - "Governo Implanta Rede", 2010) 


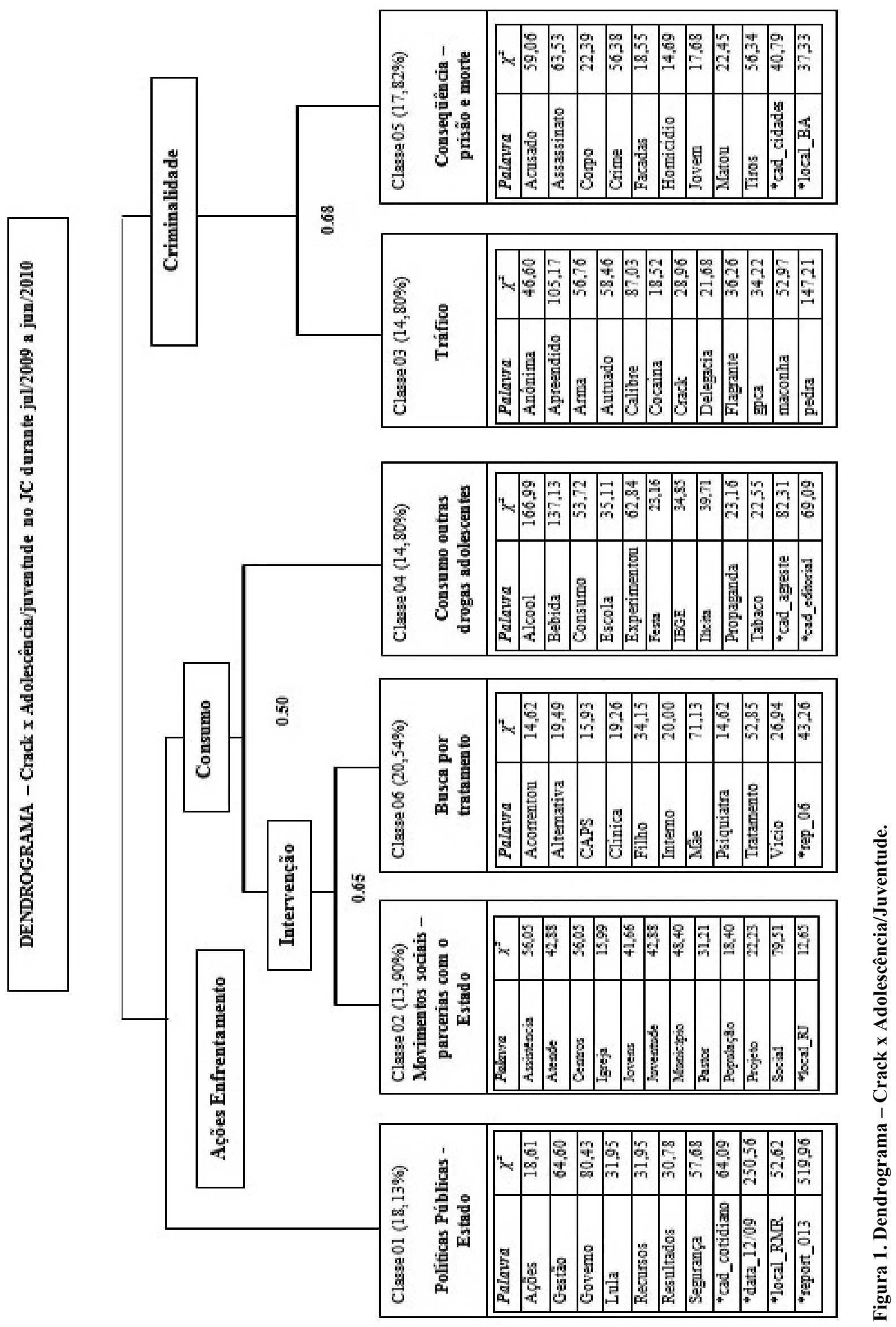


Para André Fidelis, coordenador da pastoral da juventude nos meios populares, ligada à igreja católica, a ausência do Estado nas comunidades pobres contribui para o problema. Os serviços não estão próximos e há pouco diálogo. A prefeitura do Recife lembra que o centro de atenção psicossocial CPTRA [Centro de Prevenção Tratamento e Reabilitação de Alcolismo], ao lado do hospital Ulisses Pernambucano, na Tamarineira, zona norte, tem profissionais capacitados para dar apoio e tratamento. (Classe 02 - "Muda o Comando", 2010)

A associação do Estado com os movimentos sociais para garantir o atendimento se dá prioritariamente com os movimentos religiosos, tais como a pastoral da juventude e igrejas protestantes. A prática de condução desses tratamentos oferecidos por esses grupos geralmente estão ancorados na difusão dos valores morais/religiosos e na prática da abstinência. Outras modalidades de intervenção, como a redução de danos, por exemplo, quando não são aplicadas na íntegra por falta de conhecimento e/ou capacitação técnica, são deixadas de lado ou desconsideradas.

Por outro lado, essas parcerias podem estar apontando para uma desarticulação e/ou despreparo das redes de serviço de saúde para o atendimento dos usuários. Os CAPS-ad foram pouco noticiados durante as reportagens e não foram consideradas como termos significantes pela análise realizada pelo Alceste. Do ponto de vista representacional, é possível encontrar elementos de ancoragem reproduzidos no discurso do coordenador do programa, ao justificar o histórico da ausência do Estado brasileiro para com as camadas mais carentes, sobretudo no que tange aos direitos sociais. Tal discussão não deixa de ser uma inverdade no imaginário social. Carvalho (2011) é um dos autores que discute a crença da crise Estado-nação que afetaria os direitos sociais.

Outro ponto que merece destaque é que as reportagens que mostram as parcerias entre os movimentos sociais e o Estado são em sua maioria, provenientes do Rio de Janeiro, ou seja, fora do estado de Pernambuco, local de publicação das reportagens. Poucas são as reportagens que mostram essa associação no estado de Pernambuco e em menor freqüência as que citam os CAPS-ad. Salientamos aqui, que uma das funções da mídia no estudo das representações sociais estaria em apresentar e difundir um objeto ou elementos de discussões das representações que não estejam presentes no cotidiano do grupo. Ao apresentar elementos e inserir na discussão cenas e questões de outros grupos sociais, a mídia favorece a incorporação de outros elementos representacionais, que antes não faziam parte do conhecimento daquele grupo, mas que estaria colaborando com o desenvolvimento das representações sociais (Schiele \& Boucher, 2001), do desconhecido em algo familiar, aqui, no caso específico, as práticas de intervenção com o usuário de drogas.

Em relação à classe 06, Processo de busca, é possível perceber o desespero das mães pelo tratamento dos seus filhos:

Já procurei o conselho tutelar da Iputinga, uma clínica em Afogados, mas ninguém da jeito. Não consigo nem dormir com medo dele, acrescenta. A aposentada conta que chegou a levar eletrodomésticos para a casa da vizinha, a fim de evitar os roubos praticados pelo neto. (Classe 06 - "Mais Polícia", 2010)

Josiane vai responder o processo em liberdade e disse que um ato de desespero a levou a deixar o filho preso. E triste, mas é desespero de mãe de ver o filho nesse estado e agressivo ao ponto de falar que vai matar a gente, afirmou a mulher. (Classe 06 - "Morte em Assalto", 2010)

Através dos trechos extraídos das reportagens classificadas pelo programa Alceste como mais pertinentes, pode-se observar que, diante do temor pela própria vida ou pela perda de objetos, as mães realizam uma peregrinação pelos serviços de saúde em busca do tratamento para o filho.

Ao difundirem tais reportagens, a mídia objetiva o adolescente usuário de crack como alguém dependente, fora de controle, coadunando com os achados de Santos et al. (2012), acrescentando no presente estudo elementos representacionais que demarcam a incapacidade em 
responder pelas suas faculdades mentais, pondo tanto a sua vida quanto a de outros que estão a sua volta em risco, como pais e demais familiares, por exemplo. Tais imagens ao serem difundidas socialmente criam um clima de temor entre os leitores, de que tal mal venha a acometer algum membro de sua família. Entretanto, salientamos que tais imagens/objetivações estereotipadas da figura do adolescente usuário de crack, estão de acordo com vários estudos da literatura, mas não encontram eco de todo, uma vez que há também relatos científicos de consumo moderado/pontuais de crack e outras substâncias psicoativas (German \& Sterk, 2002; Silveira \& Rodrigues, 2013).

Outras mães, por não encontrarem locais adequados para tratamento e por desespero, terminam utilizando recursos últimos, como acorrentar o filho para que ele não saia para consumir mais droga ou tenha acessos de violência causados pela abstinência. $\mathrm{O}$ ato de acorrentar os filhos revela outro conteúdo imagético/objetivação da representação social de adolescente e crack - um jovem descontrolado, acorrentado, um animal selvagem. Há uma perda da personalidade humana do jovem usuário em detrimento de uma nova ordem imagética, a de um animal selvagem.

É possível verificar nas reportagens a associação entre violência e consumo de drogas. Todavia, em estudo publicado por E. F. Silva et al. (2006), os autores mostram que essa associação é falha, pois segundo os mesmos: "tais relações causais não foram comprovadas em virtude de se tratarem de associações complexas e multilineares, comprovando-se apenas associação entre drogas e violência, especialmente no tráfico de drogas ilegais" (E. F. Silva et al., 2006, p. 1151). A associação entre o tráfico de drogas e violência será discutida na relação entre as classes 03 e 05 .

O sofrimento pela perda de bens também é mostrado nas reportagens.

A mãe não aguenta mais ir buscar o filho na boca de fumo sem roupa e ver os últimos bens sendo retirados de casa para saldar dívidas com traficantes, afirma Flavio Almeida Junior (Classe 06 - "Viciado em Crack", 2010).
A classe 04 apresenta uma pesquisa que aponta para o consumo de outras substâncias além do crack. Segundo pesquisa realizada pelo Instituto Brasileiro de Geografia e Estatística (IBGE, 2010), apesar do consumo de crack ser preocupante, outras substâncias também estão sendo consumidas pelos jovens. O álcool foi apontado pela pesquisa como a substância mais consumida e que cada vez os jovens estão ingerindo mais cedo.

Levantamento do IBGE sobre a saúde dos estudantes brasileiros mostra que maioria dos adolescentes menores de 15 anos já experimentou bebida alcoólica. Sete em cada dez adolescentes brasileiros entre 13 e 15 anos já consumiram bebida alcoólica (Classe 04 - "Operação Padrão", 2009). . . Elevando os riscos de aguçar a curiosidade para as drogas pesadas. Segundo levantamento feito pelo IBGE, com 63 mil estudantes de escolas públicas e privadas, nada menos que $70 \%$ dos alunos entre 13 e 15 anos admitiram ter experimentado a bebida alcoólica. (Classe 04 - "Jovem Usuário de Droga", 2012)

A discussão em torno do consumo de outras substâncias por parte dos jovens também gera preocupação às escolas, familiares e serviços de saúde. A ideia da escalada da droga está relacionada ao consumo de álcool na adolescência. Para a imprensa pesquisada, o álcool seria um dos elementos preocupantes juntamente com outras substâncias psicoativas representadas como mais perigosas e causadoras de dependência, como o cigarro, maconha, cocaína e crack, por exemplo. Essa discussão encontra respaldo em estudos, tais como Gomes, Alves e Nascimento (2010), Moreno, Ventura e Brêtas (2010) e Pinsky, Zaleski, Laranjeira, e Caetano (2010), os quais apresentam resultados levantando a preocupação do consumo precoce do álcool entre a população e alertando aos possíveis riscos do consumo nessa faixa etária.

O segundo grande eixo - Criminalidade, é composto pela junção das classes 03 , Tráfico e 05, Conseqüência - prisão e morte. Enquanto o grande eixo anterior apresentava a relação do adolescente com a droga pelo viés de usuário e 
dependente, este eixo mostra esta relação a partir do outro lado do consumo da droga, o adolescente traficante envolvido com o crime. Tais concepções também foram encontradas por Santos et al. (2012), os quais relataram a representação do crack na imprensa pernambucana pautada na figura do traficante, criminoso e em associação com a morte.

Outro elemento da representação do adolescente e crack na imprensa está no tráfico, conforme se verifica na classe 03 . Ao mesmo tempo que o adolescente é objetivado na imagem do dependente, a referência imagética de criminoso também se faz presente como outro elemento de objetivação. Os relatos selecionados abaixo expressam essa questão:

A polícia apreendeu, na tarde desta sexta-feira, 11, um adolescente de 17 anos que estava com 50 pedras de crack. Um revolver calibre 38 e $R \$ 20,00$ também foram apreendidos com o garoto (Classe 03 "Polícia Investe Pesado", 2009).

Um jovem de 15 anos também foi apreendido e encaminhado a gerencia de polícia da criança e do adolescente, GPCA. Outro homem suspeito conseguiu fugir. A polícia encontrou com os acusados 85 pedras de crack, dois revolveres calibre 38 e 17 projeteis. Segundo o delegado Marcelo Ferraz, responsável pelo caso, os agentes chegaram aos traficantes graças a denúncias anônimas. (Classe 03 - "Cai o Número", 2009)

A forma como a imprensa apresenta o adolescente envolvido com o crime se dá com uma arma atuando junto ao tráfico. Essa outra dimensão da representação do adolescente envolvido com o crack - traficante, geralmente se mostra como vendedor e/ou alguém que está transportando a droga para algum lugar, personagem nomeado como vapor. Zaluar (2012) e Zaluar e Barcellos (2013) discutem as trajetórias e modos de inserção dos adolescentes e jovens, via tráfico de drogas e o alto número de mortes em conflitos violentos com os dispositivos de segurança pública.

A correlação apresentada pelo software Alceste de 0,68 entre as classes do Tráfico e Conseqüencia - prisão e morte podem ser entendi- das como uma relação de causa e consequência. Os resultados mostram que seria quase que uma associação direta entre o tráfico, com a prisão e morte (classe 05).

Um adolescente de 14 anos foi assassinado a tiros dentro de uma casa na rua da união, no bairro de campo grande, zona norte do Recife. Segundo a polícia, Elenilson Ferreira de Franca estaria queimando crack com três amigos quando dois homens armados teriam entrado na residência, na madrugada desta terça-feira, 27. (Classe 05 - "Em Dois Meses", 2010)

Uma jovem de 18 anos foi morta a tiros no bairro do Ibura, zona sul do Recife. A polícia militar de Pernambuco suspeita que o crime tenha motivação passional e que também tenha relações com o tráfico de drogas (Classe 05 -"Ministério Reúne Prefeitos", 2009).

A morte é outro elemento presente na representação veiculada pela imprensa. Ao ler as reportagens e comparar com a análise proposta pelo Alceste, percebe-se que tal fenômeno está relacionado à representação do adolescente traficante e não a do consumidor. No momento que o adolescente passa a se envolver com o tráfico, tal escolha passa a se constituir em um caminho sem volta. A prisão e a morte são representados socialmente como uma certeza na vida dos jovens traficantes, coadunando com os achados de Santos et al. (2012). A morte encontra espaço para ancorar-se em conhecimentos prévios do grupo, uma vez que o estado de Pernambuco apresenta um dos maiores índices nacionais de mortes de jovens por armas de fogo, segundo os indicadores de saúde presentes no levantamento realizado pelo IBGE (2010) sobre a avaliação do impacto das causas violentas no Brasil.

O modo como a imprensa relaciona os adolescentes com o crack parece estar ligado à condição socioeconômica. Se por um lado o envolvimento com o consumo e dependência pode acontecer com qualquer adolescente de modo indiscriminado, o crime e tráfico são associados aos adolescentes de baixa renda. Se a associação entre pobreza e violência ainda é constatada como elemento de representação em vários gru- 
pos sociais, Santos, Aléssio e Silva (2009), L. A. M. Silva (2010) e Vianna e Neves (2011), observou-se no presente estudo que outro elemento contemporâneo, a drogadição, também passou a fazer parte dessa associação nos discursos sociais. As mortes dos jovens das camadas mais baixas são noticiadas pela mídia devido ao seu envolvimento com as drogas via tráfico.

\section{Considerações Finais}

Os dados analisados neste estudo permitem constatar algo que a leitura cotidiana dos jornais apontava a associação da parcela jovem com o crack. Contudo, o modo como se dava essa associação foi descortinada. Os sentidos apresentados pela mídia impressa pesquisa para a relação da adolescência e o crack está pautado em torno de dois grandes eixos de sentido, o tratamento, via internação quase sem sucesso, ou a morte, pelo tráfico de drogas. Nessas duas possibilidades, apesar do caminho percorrido, a vivência do sofrimento e dor dos familiares demarca os dois trajetos de vivência com a droga por parte do adolescente.

$\mathrm{O}$ envolvimento dos adolescentes com o crack se dá por duas imagens polarizadas objetivadas, a figura do usuário ou traficante. O primeiro traz ligado a si o sofrimento e o desespero dos profissionais dos familiares com o envolvimento do filho e o despreparo do Estado no atendimento ao usuário e enfrentamento da questão. Discursos de escalada ou progressão da droga vêm à tona nas reportagens e a necessidade de estratégias preventivas são presentes.

O temor noticiado e apresentado aos leitores é do filho iniciar no álcool e progredir rapidamente por outras drogas até chegar ao crack. Apesar de vários estudos demonstrarem a preocupação do envolvimento com o álcool durante a adolescência e dos males que podem advir desse consumo, poucos são os que discutem e apresentam a escalada das drogas.

Caso o adolescente não se vincule à droga via dependência a outra condição esperada é pelo tráfico. Para este, o resultado final é a prisão ou morte. A representação social da relação do adolescente com o crack veiculada pela impren- sa está pautada na concepção de que não há saída caso o jovem se envolva com o crack. Novamente, o sofrimento e dor dos familiares são condições sine qua non nesta relação.

Do ponto de vista teórico, a imprensa seria o mediador entre o universo reificado e o consensual, colaborando assim para a construção das representações sociais. Observamos a importância desse estudo ao passo que os leitores ao terem acesso aos conteúdos veiculados nas versões impressas e on line receberem informações que servirão de base para a construção e manutenção de suas representações. $O$ temor e alarde provocado pela droga encontram na imprensa o seu canal emissor.

Por fim, destacamos que o presente estudo debruçou-se sobre o envolvimento da adolescência com o crack, na imprensa escrita. Contudo, reforçamos a necessidade de outros estudos que venham a alargar a compreensão do fenômeno. A proposta apresenta foi a de apresentar como a imprensa representa e compreende tal fenômeno, entendo que as representações veiculadas pela imprensa contribuem sobremodo para o entendimento e significação da realidade por parte dos diversos públicos leitores do jornal.

\section{Referências}

Araújo, L. F., Castanha, A. R., Barros, A. P. R., \& Castanha, C. R. (2006). Estudo das representações sociais da maconha entre agentes comunitários de saúde. Ciência \& Saúde Coletiva, 11(3), 827836. doi:10.1590/S1413-81232006000300030

Araújo, L. F., Gontiès, B., \& Nunes, J., Jr. (2007). Representações sociais da cocaína: Estudo comparativo entre estudantes das áreas de saúde e jurídica. Estudos de Psicologia (Campinas), 24(3), 315-323 doi:10.1590/S0103$-166 \mathrm{X} 2007000300003$

Baus, J., Kupek, E., \& Pires, M. (2002). Prevalência e fatores de risco relacionados ao uso de drogas entre escolares. Revista de Saúde Pública, 36, 40-46. doi:10.1590/S0034-89102002000100007

Cai o número de assaltos a ônibus. (2009, 10 set.). JC on line. Recuperado em http://jconlinedigital. ne10.uol.com.br/web/

Carvalho, J. M. (2011). Cidadania no Brasil: Um longo caminho. Rio de Janeiro, RJ: Civilização Brasileira. 
Chen, N. Y., \& Anthony, J. C. (2004). Epidemiological estimates of risk in the process of becoming dependent upon cocaine: Cocaine hydrochloride powder versus crack cocaine. Psychopharmacology, 172(1), 78-86. doi:10.1007/s00213-003-1624-6

Coutinho, M. P. L., Araújo, L. F., \& Gontiès, B. (2004). Uso da maconha e suas representações sociais: Estudo comparativo entre universitários. Psicologia em Estudo, 9(3), 469-477. doi:10.1590/S1413-73722004000300015

De Micheli, D., \& Formigoni, M. L. (2004). Drug use by Brazilian students: Associations with family, psychosocial, health, demographic and behavioral characteristics. Addiction, 99(5), 570-578. doi:10.1111/j.1360-0443.2003.00671.x

Em dois meses, 647 pessoas assassinadas. (2010, 09 abr.). JC on line. Recuperado em http://jconlinedigital.ne10.uol.com.br/web/

Fonseca, A. A., Azevedo, R. L. W., Araújo, L. F., Oliveira, S. F., \& Coutinho, M. P. L. (2007). Representações sociais de universitários de psicologia acerca da maconha. Estudos de Psicologia (Campinas), 24(4), 441-449. doi:10.1590/ S0103-166X2007000400004

Fundação Osvaldo Cruz, \& Secretaria Nacional de Políticas sobre Drogas. (2013). Estimativa do número de usuários de crack elou similares nas capitais do pais. Rio de Janeiro, RJ: Fundação Osvaldo Cruz.

German, D., \& Sterk, C. E. (2002). Looking beyond stereotypes: Exploring variations among crack smokers. Journal Psychoactive Drugs, 34(4), 383-392.

Giacomozzi, A. I. (2011). Representações sociais da droga e vulnerabilidade de usuários de CAPSad em relação a DST/HIV/AIDS. Estudos e Pesquisas em Psicologia, 11(3), 776-795.

Gomes, B. M. R., Alves, J. G. B., \& Nascimento, L. C. (2010). Consumo de álcool entre estudantes de escolas públicas da Região Metropolitana do Recife, Pernambuco, Brasil. Cadernos de Saúde Pública, 26(4), 706-712.

Governo implanta rede de dados para auxiliar segurança. (2010, 20 jun.). JC on line. Recuperado em http://jconlinedigital.ne10.uol.com.br/web/

Guimarães, J. L, Godinho, P. H., Cruz, R., Kappann, J. I., \& Tosta, L. A., Jr. (2004). Consumo de drogas psicoativas por adolescentes escolares de Assis, SP. Revista de Saúde Pública, 38(1), 130132. doi:10.1590/S0034-89102004000100018
As imagens de uma guerra particular. (2009, 08 dez.). $J C$ on line. Recuperado em http://jconlinedigital. ne10.uol.com.br/web/

Instituto Brasileiro de Geografia e Estatística. (2010). A qualidade da informação sobre a mortalidade no Brasil recente e avaliação do impacto das causas violentas no número de anos de vida perdidos, 2009. Recuperado em http://www.ibge. gov.br/home/estatistica/populacao/indic_sociosaude/2009/com_aquali.pdf

Jodelet, D. (2001). As representações sociais. Rio de Janeiro, RJ: Editora da Universidade do Estado do Rio de Janeiro.

Jovem usuário de droga é morto a facadas por causa de dívida de R\$ 8. (2012, 15 jan.). JC on line. Recuperado em http://jconlinedigital.ne10.uol. com.br/web/

Mais polícia, médicos e verba contra o crack. (2010, 27 maio). JC on line. Recuperado em http:// jconlinedigital.ne10.uol.com.br/web/

Medeiros, K. T., Maciel, S. C., Sousa, P. F., Tenorio-Sousa, F. M., \& Dias, C. C. V. (2013). Representações sociais do uso de drogas entre familiares de usuários. Psicologia em Estudo, 18(2), 269279. doi:10.1590/S1413-73722013000200008

Ministério reúne prefeitos de cidades violentas. (2009, 06 dez.). JC on line. Recuperado em http://jconlinedigital.ne10.uol.com.br/web/

Moreno, R. S., Ventura, R. N., \& Brêtas, J. R. S. (2010). O uso de álcool e tabaco por adolescentes do município de Embu, São Paulo, Brasil. Revista da Escola de Enfermagem da USP, 44(4), 969-977.

Morte em assalto a sulanqueiros. (2010, 19 mar.). $J C$ on line. Recuperado em http://jconlinedigital. ne10.uol.com.br/web/

Moscovici, S. (1961). La Psychanalyse, son image et son publique. Paris: Presses Universitaires de France.

Muda o comando da segurança pública. $(2010,19$ abr.). JC on line. Recuperado em http://jconlinedigital.ne10.uol.com.br/web/

Nappo, S. A., Galduróz, J. C., Raymundo, M., \& Carlini, E. A. (1999). Changes in cocaine use as viewed by key informants: A qualitative study carried out in 1994 and 1999 in São Paulo, Brazil. Journal Psychoactive Drugs, 33(3), 241-53.

Noto, A. R., Pinsky, I., \& Mastroianni, F. C. (2006). Drugs in the Brazilian Print Media: An exploratory survey of newspaper and magazine stories 
in the year 2000. Substance Use \& Misuse, 41(9), 1263-1276. doi:10.1080/10826080600754868

Oliveira, J. F., McCallum, C. A., \& Costa, H. O. G. (2010). Representações sociais de agentes comunitários de saúde acerca do consumo de drogas. Revista da Escola de Enfermagem da USP, 44(3), 611-618. doi:10.1590/S008062342010000300009

Oliveira, L. G., \& Nappo, S. A. (2008). Crack na cidade de São Paulo: Acessibilidade, estratégias de mercado e formas de uso. Revista de Psiquiatria Clínica, 35(6), 212-218. doi:10.1590/ S0101-60832008000600002

Operação padrão na Polícia Civil. (2009, 23 dez.). JC on line. Recuperado em http://jconlinedigital. ne10.uol.com.br/web/

Pinsky, I., Zaleski, M., Laranjeira, R., \& Caetano, R. (2010). Primeiro levantamento nacional sobre os padrões de consumo de álcool na população brasileira. Revista Brasileira de Psiquiatria, 32(3), 214-215 doi:10.1590/S151644462010000300003

Polícia investe pesado contra o Crack. (2009, 5 dez). JC on line. Recuperado em http://jconlinedigital. ne10.uol.com.br/web/

Raupp, L., \& Adorno, R. C. F. (2011). Circuitos de uso de crack na região central da cidade de São Paulo (SP, Brasil). Ciência \& Saúde Coletiva, 16(5), 2613-2622. doi:10.1590/S141381232011000500031

Reinert, M. (1990). Alceste, une méthotodologie d'analyse des donnés textuelles et une application: Aurelia de Gerard de Nerval. Bulletin de Méthodologie, 26, 24-54.

Rodrigues, T. M. S. (2002). A infindável guerra americana: Brasil, EUA e o narcotráfico no continente. São Paulo em Perspectiva, 16(2), 102111. doi:10.1590/S0102-88392002000200012

Santos, M. F. S., Acioli, M. L., Neto, \& Sousa, Y. S. O. (2012). Representações sociais do crack na imprensa pernambucana. Estudos de Psicologia (Campinas), 29(3), 379-386. doi:10.1590/ S0103-166X2012000300008

Santos, M. F. S., Aléssio, R. L. S., \& Silva, J. M. M. N. (2009). Os adolescentes e a violência na imprensa. Psicologia: Teoria e Pesquisa, 25(3), $447-$ 452. doi:10.1590/S0102-37722009000300020

Santoucy, L. B., Conceição, M. I. G., \& Sudbrack, M. F. O. (2010). A compreensão dos operado- res de direito do Distrito Federal sobre o usuário de drogas da vigência da nova lei. Psicologia: Reflexão e Crítica, 23(1), 176-185. doi:10.1590/ S0102-79722010000100021

Schiele, B., \& Boucher, L. (2001). A exposição científica: Uma maneira de representar a ciência. In D. Jodelet, As representações sociais (pp. 363378). Rio de Janeiro, RJ: Editora da Universidade do Estado do Rio de Janeiro.

Silva, E. F., Pavani, R. A. B., Moraes, M. S., \& Chiaravalloti, F. C., Neto. (2006). Prevalência do uso de drogas entre escolares do ensino médio do Município de São José do Rio Preto, São Paulo, Brasil. Cadernos Saúde Pública, 22(6), 11511158. doi:10.1590/S0102-311X2006000600004

Silva, L. A. M. (2010). "Violência urbana”, segurança pública e favelas: O caso do Rio de Janeiro atual. Caderno CRH, 23(59), 283-300. doi:10.1590/ S0103-49792010000200006

Silveira, G. L., \& Rodrigues, L. B. (2013). O consumo de substâncias psicoativas e o autocuidado entre pessoas em situação de rua na cidade de Juazeiro-BA. Revista Psicologia, Diversidade e Saúde, 2(1), 95-122.

Soldera, M., Dalgalarrondo, P., Corrêa, H. R., Filho, \& Silva, C. A. M. (2004). Uso de drogas psicotrópicas por estudantes: Prevalência e fatores sociais associados. Revista de Saúde Pública, 38(2), 277-283. doi:10.1590/S003489102004000200018

Vianna, P. C., \& Neves, C. E. A. B. (2011). Dispositivos de repressão e varejo do tráfico de drogas: Reflexões acerca do Racismo de Estado. Estudos de Psicologia (Natal), 16(1), 31-38. doi:10.1590/S1413-294X2011000100005

Viciado em crack recebe proteção. (2010, 01 jun.). JC on line. Recuperado em http://jconlinedigital. ne10.uol.com.br/web/

Zaluar, A. (2012). Juventude violenta: Processos, retrocessos e novos percursos. Dados, 55(2), 327365. doi:10.1590/S0011-52582012000200003

Zaluar, A., \& Barcellos, C. (2013). Mortes prematuras e conflito armado pelo domínio das favelas no Rio de Janeiro. Revista Brasileira de Ciências Sociais, 28(81), 17-31. doi:10.1590/S010269092013000100002

Recebido: $12 / 12 / 2013$

$1^{a}$ revisão: $1 \% 05 / 2014$ Aceite final: $15 / 07 / 2014$ 